\title{
PENGEMBANGAN SKALA DECEPTION BEHAVIOR IN SOCIAL MEDIA
}

\section{Clara Moningka ${ }^{1}$ \& Selviana $^{2}$}

${ }^{1}$ Fakultas Bisnis dan Humaniora, Program Studi Psikologi, Universitas Pembangunan Jaya, Jl. Cendrawasih Raya Blok B7/P, Tangerang Selatan, Banten 15413, Indonesia

${ }^{2}$ Fakultas Psikologi, Universitas Persada Indonesia YAI, Jl. Diponegoro No.74, Jakarta Pusat 10430, Indonesia

Korespondensi: clara.moningka@upj.ac.id; selvi.humble@gmail.com

\section{THE DEVELOPMENT OF DECEPTION BEHAVIOR IN SOCIAL MEDIA SCALE}

\begin{abstract}
The advancement of Internet worldwide has led to a new phenomena of the use of social media. Social media is used not only to connect to other people but to create good impression that sometimes involves deceiving. Social media users often manipulate their appearance in social media, such as editing their photos or faking their identities. This phenomenon is categorized as deception behavior. While this is an emerging phenomenon, there has been lack of studies that attempt to measure an individual's intention to involve in deception behavior in social media. The aim of this study is to construct Deception Behavior in Social Media Scale based on the Utz's (2005) theory. The respondents of this study were 457 active social media users in Jakarta and greater areas with an age ranged from 15-40 years. This study included item making and tested the scale using Component Analysis (PCA) followed by second order Confirmatory Factor Analysis (CFA). Reliability testing was performed using Cronbach's alpha coefficient. The result showed that this scale is reliable measure deception behavior in social media.
\end{abstract}

Manuscript type: Original Research

\section{Article history:}

Received 3 January 2020

Received in revised form 16 April 2020

Accepted 9 July 2020

Available online 18 November 2020

\section{Keywords:}

deception behavior

internet

social media

\begin{abstract}
Abstrak
Kemajuan teknologi Internet di dunia memunculkan fenomena baru dalam penggunaan media sosial. Media sosial tidak hanya digunakan untuk berhubungan dengan orang lain, namun juga untuk membentuk kesan yang baik, bahkan untuk melakukan manipulasi. Pengguna media sosial seringkali memanipulasi penampakan mereka di media sosial, seperti mengedit foto atau memalsukan identitas mereka. Fenomena ini termasuk dalam Deception Behavior (perilaku menipu). Meski fenomena ini sering dijumpai, belum banyak studi yang berupaya untuk mengukur kecenderungan seseorang untuk terlibat dalam perilaku menipu di media sosial. Oleh karena itu, penelitian ini bertujuan untuk membuat skala Deception Behavior in Social Media berdasarkan teori Utz (2005). Partisipan penelitian adalah pengguna aktif media sosial sebanyak 457 orang di wilayah Jabodetabek dengan rentang usia 15-40 tahun. Penelitian ini meliputi pembuatan butir dan pengujian dengan menggunakan Principal Component Analysis (PCA), dilanjutkan dengan Confirmatory Factor Analysis (CFA). Sementara itu, reliabilitas diuji dengan menggunakan koefisien Cronbach's Alpha. Hasil penelitian menunjukkan bahwa skala ini reliabel untuk mengukur deception behavior di media sosial.
\end{abstract}

Kata Kunci: deception behavior, internet, media sosial

\section{Dampak dan Implikasi dalam Konteks Ulayat}

Penelitian ini secara khusus dapat memberi kontribusi ilmiah pada pengembangan alat ukur psikologi dalam berperilaku di media sosial pada orang Indonesia. Data terbaru menunjukkan terdapat sebanyak sekitar 150 juta orang pengguna media sosial aktif di Indonesia dan sampai saat ini penggunanya terus bertambah mengingat berbagai aktivitas masyarakat modern mengarah kepada penggunaan teknologi secara daring. Hal ini sangat memungkinkan munculnya berbagai perilaku dalam bermedia sosial yang khas pada budaya Indonesia. Dalam hal ini, skala Deception Behavior in Social Media dapat dimanfaatkan untuk melihat bagaimana pengguna media sosial menutupi atau mengubah identitas diri yang lebih baik. 


\section{PENDAHULUAN}

Kemajuan teknologi Internet di dunia memunculkan fenomena baru dalam penggunaan media sosial. Media sosial tidak hanya digunakan untuk berhubungan dengan orang lain, namun juga untuk menampilkan citra diri yang lebih baik. Banyak pengguna media sosial memanipulasi citra diri atau gambaran dirinya, bahkan sampai dapat memalsukan identitas di media sosial agar dapat terlihat baik, menyenangkan, dan dapat dipercaya. Fenomena ini disebut deception behavior (perilaku menipu atau mengelabui). Burgoon dan Levine (2010) menggambarkan deception behavior sebagai tindakan yang dilakukan secara sengaja untuk membuat orang lain mempercayai atau meyakini sesuatu yang tidak sesuai dengan kenyataannya. Deception behavior dapat berwujud mengubah, mengada-ada, melebih-lebihkan, menutupi, dengan sengaja membuat kesalahpahaman, menghilangkan atau menyembunyikan sesuatu (Burgoon \& Levine, 2010).

Dalam kaitannya dengan penggunaan media sosial saat ini, sering ditemukan beberapa perilaku seperti mengedit foto untuk menampilkan kondisi yang terbaik, bahkan membuat informasi, data diri, atau menjual produk yang tidak sesuai. Tidak jarang juga ditemukan perilaku memberikan komentar yang memicu perdebatan. Moningka (2017) mengemukakan bahwa proses perbandingan sosial di media sosial atau dunia maya membuat individu ingin menampilkan dirinya dengan baik. Sanderson (2010) menyatakan bahwa individu kerap meragukan kemampuan atau penampilan mereka. Perilaku yang muncul akibat perbandingan sosial tersebut dapat mengarah pada perilaku menutupi atau melebih-lebihkan penampilan. Gejala ini termasuk dalam deception behavior. Konsep deception behavior sendiri masih jarang diteliti sebagai suatu variabel psikologi, sehingga upaya dalam pengembangan alat ukurnya menjadi kebutuhan yang dianggap penting dan perlu untuk menjadikannya sebagai suatu konstruk yang lebih terukur pada penelitian-penelitian

psikologi, khususnya dalam ranah cyber psychology. Secara khusus, penelitian ini hendak membuat skala deception behavior in social media dari teori Utz (2005) terkait jenis-jenis deception behavior, antara lain mengubah gender atau identitas, menampilkan diri lebih baik, dan menutupi identitas yang butir-butirnya disusun sendiri oleh peneliti.

Pengguna media sosial aktif di Indonesia mencapai angka 150 juta orang, di mana angka ini merupakan kenaikan 15\% (sekitar 20 juta populasi) dari tahun 2018 (Hootsuite, 2019). Pengguna media sosial biasanya menggunakan empat perangkat media sosial terbesar, seperti Youtube (88\%), Whatsapp (83\%), Facebook (81\%), dan Instagram (80\%). Data ini menunjukkan peningkatan pengguna media sosial dan menunjukkan bahwa media sosial menjadi bagian yang tidak dapat 
terpisahkan dari kehidupan manusia modern yang di dalamnya terdapat banyak hal yang dapat dicermati, termasuk deception behavior. Oleh karena itu, pengembangan skala social media deception behavior ini dirasa perlu dilakukan.

Berdasarkan diskusi kelompok (Focus Group Discussion; FGD) yang dilakukan untuk mengidentifikasi deception behavior di media sosial, diperoleh hasil bahwa alasan pengguna media sosial melakukan deception behavior adalah untuk hiburan semata. Selain itu, alasan lain yang juga ditemukan adalah agar dapat menampilkan versi terbaik dari diri sendiri, mendapatkan kenalan baru, mendapatkan pengakuan publik, membanggakan diri, dan tidak kalah bersaing dengan teman lain. Adanya perasaan ingin diakui keberadaannya membuat setiap individu berlomba-lomba untuk menunjukkan dirinya kepada dunia luar dan media sosial menjadi sarana individu untuk mengiklankan diri (branding) melalui tautan yang dibagikan lewat foto, video, maupun pernyataan yang dibuat semenarik mungkin (Hootsuite, 2019).

Lebih lanjut, individu berusaha untuk menampilkan diri agar mendapatkan tanggapan positif sebanyak mungkin dari orang lain. Hayuputri (2019) mengemukakan bahwa salah satu hal yang juga banyak ditemui di media sosial Indonesia pada masa ini adalah akun palsu. Tidak dapat dipungkiri bahwa setiap individu memiliki kecenderungan untuk membuat citra positif di media sosialnya. Hal ini mendorong individu tersebut harus menampilkan hal-hal yang baik saja dan merasa memiliki keterbatasan dalam menuangkan perasaan dan ekspresi yang sesungguhnya. Mengacu pada alasan tersebut, dibuatlah akun palsu agar individu dapat mengekspresikan dirinya dengan cara yang lain. Fenomena-fenomena seperti inilah yang dapat memicu seseorang melakukan deception behavior di media sosialnya.

Berdasarkan penjelasan di atas, penelitian ini secara khusus hendak menyusun dan menguji skala Deception Behavior in Social Media pada pengguna media sosial yang tersusun atas butirbutir yang baik dan sesuai dengan standar psikometri yang memadai, serta diharapkan dapat menjadi sumbangan alat ukur baru dalam penelitian psikologi, khususnya yang terkait dengan aktivitas di dunia maya.

\section{Pengertian Deception Behavior}

Istilah deception behavior masih jarang digunakan sebagai suatu konstruk dalam penelitian psikologi. Meskipun demikian, kemajuan teknologi membuat gejala tersebut dapat terlihat pada pengguna media sosial masa kini. Carson (2010) mendefinisikan deception behavior sebagai suatu perbuatan yang dilakukan secara sengaja untuk membuat orang lain percaya akan sesuatu yang 
tidak benar. Deception (menipu) berbeda dengan lying (berbohong) (Carson, 2010). Lying adalah mengatakan sesuatu yang tidak benar, sedangkan deception adalah membuat orang lain mempercayai sesuatu yang tidak benar. Lying biasanya berbentuk verbal, sedangkan deception dapat dilakukan secara verbal maupun non-verbal. Dengan kata lain, individu dapat dikatakan melakukan deception jika individu tersebut membuat orang lain mempercayai sesuatu yang diketahuinya tidak benar. Knapp dkk. (2016) menyatakan bahwa lying dan deception merupakan suatu bentuk komunikasi dan dapat dilakukan dalam berbagai konteks. Hanya saja, lying dapat dilakukan secara tidak sengaja atau karena situasi terdesak, sedangkan deception dilakukan secara sengaja untuk mengelabui orang lain agar mempercayainya. Dapat dikatakan bahwa deception behavior merupakan perilaku yang secara sengaja dilakukan untuk membuat orang lain mempercayai sesuatu yang salah.

Whitty dan Young (2017) mengemukakan bahwa deception in cyberspace merupakan kontrol yang sengaja dilakukan dalam memuat informasi yang disebarkan secara online untuk menciptakan kepercayaan yang salah pada penerima pesan. Hal ini memang terjadi di media sosial yang dijadikan sebagai sarana untuk menyebarkan informasi-informasi tertentu agar penerima pesannya percaya pada informasi yang diberikan.

Berdasarkan uraian di atas, dalam penelitian ini deception behavior didefinisikan sebagai tindakan yang dilakukan secara sengaja untuk membuat orang lain percaya akan sesuatu yang tidak benar dan merupakan tindakan mengelabui.

\section{Jenis-jenis Deception Behavior}

Dalam penelitian ini, secara khusus peneliti hendak membuat skala deception behavior pada pengguna media sosial berdasarkan teori Utz (2005) yang menyatakan bahwa deception behavior pada dunia maya (cyber) dibagi menjadi tiga jenis, yaitu: 1). mengubah gender atau identitas, misalnya seseorang berjenis kelamin laki-laki berpura-pura menjadi perempuan dan atau sebaliknya; 2). menampilkan diri lebih baik dan menampilkan ciri fisik yang lebih menarik, seperti penampilan yang lebih kurus, lebih menawan, dan lebih kaya; dan 3). menutupi identitas, yaitu menggunakan nama yang salah atau bukan nama sebenarnya, serta mencuri identitas seseorang dan berpura-pura menjadi orang tersebut. Dalam penelitian ini, peneliti menggunakan teori jenis-jenis deception behavior ini untuk mengukur deception behavior pada pengguna media sosial di Jabodetabek. 


\section{METODE}

\section{Partisipan}

Penelitian ini menggunakan teknik aksidental, yaitu pengambilan partisipan yang mudah dijangkau dengan kriteria pengguna media sosial aktif pada area penelitian yang tersebar di Jakarta, Bogor, Depok, Tangerang, dan Bekasi (Jabodetabek). Partisipan pada penelitian ini berjumlah 457 orang. Dengan jumlah responden yang besar dan heterogen, maka penelitian ini diharapkan menghasilkan perhitungan statistik yang lebih baik. Data demografis partisipan penelitian dapat dilihat pada Tabel 1.

Tabel 1.

Data Demografis Partisipan Penelitian

\begin{tabular}{|c|c|c|}
\hline \multicolumn{2}{|c|}{ Data Demografis } & \multirow{2}{*}{$\begin{array}{c}\text { Jumlah } \\
344(75.3 \%)\end{array}$} \\
\hline \multirow{3}{*}{ Jenis Kelamin } & Perempuan & \\
\hline & Laki-laki & $113(24.7 \%)$ \\
\hline & Total & $457(100 \%)$ \\
\hline \multirow{6}{*}{ Usia } & 15-18 tahun & $77(16.8 \%)$ \\
\hline & 19-24 tahun & $274(60 \%)$ \\
\hline & 25-30 tahun & $36(7.9 \%)$ \\
\hline & $31-40$ tahun & $42(9.2 \%)$ \\
\hline & $>40$ tahun & $28(6.1 \%)$ \\
\hline & Total & $457(100 \%)$ \\
\hline \multirow{5}{*}{ Pekerjaan } & Pelajar & $293(64.1 \%)$ \\
\hline & Karyawan swasta & $82(17.9 \%)$ \\
\hline & Guru/dosen & $36(7.9 \%)$ \\
\hline & Profesi lain & $46(10.1 \%)$ \\
\hline & Total & $457(100 \%)$ \\
\hline \multirow{5}{*}{ Pendidikan } & SMA & $328(71.8 \%)$ \\
\hline & S1 & $84(18.4 \%)$ \\
\hline & S2 & $35(7.7 \%)$ \\
\hline & Lainnya & $10(2.1 \%)$ \\
\hline & Total & $457(100 \%)$ \\
\hline
\end{tabular}

\section{Desain}

Penelitian ini merupakan penelitian kuantitatif yang bertujuan menguji suatu alat ukur baru, yaitu Deception Behavior in Social Media. Dalam penelitian ini, deception behavior diartikan sebagai tindakan yang dilakukan secara sengaja untuk membuat orang lain percaya akan sesuatu yang tidak benar. 
Peneliti mengkonstruksi skala Deception Behavior in Social Media berdasarkan jenis-jenis deception behavior dari Utz (2005) yang butir-butirnya disusun sendiri oleh peneliti. Pada penelitian ini, butir yang dibuat hanya berjumlah 10 pernyataan untuk ketiga jenis deception behavior dan menggunakan skala Likert dengan rentang angka 1-5 (Sangat Tidak Sesuai sampai dengan Sangat Sesuai). Butir-butir dalam skala ini memang dibuat sedikit dengan beberapa pertimbangan, antara lain efektivitas waktu menjawab. Selain itu, pada skala ini peneliti tidak membuat pernyataan yang unfavorable agar mengurangi bias sosial partisipan dalam mengisi kuisioner penelitian, serta mempertimbangkan terjadinya tumpang-tindih pada jenis-jenis deception behavior yang tampak saling berkaitan, yaitu mengubah identitas dan menutupi identitas. Di bawah ini adalah Tabel 2 yang memuat sebaran butir-butir skala Deception Behavior in Social Media.

Tabel 2.

Butir Skala Deception Behavior in Social Media

\begin{tabular}{|c|c|c|}
\hline Jenis & No & $\begin{array}{c}\text { Yang saya lakukan di media sosial } \\
\text { antara lain... }\end{array}$ \\
\hline \multirow{3}{*}{ Mengubah identitas } & 1 & $\begin{array}{c}\text { Menampilkan status sosial yang lebih tinggi agar terlihat baik bagi } \\
\text { orang lain. }\end{array}$ \\
\hline & 2 & Menampilkan foto-foto yang bukan diri saya pada media sosial. \\
\hline & 8 & Menggunakan nama akun yang berbeda dengan nama asli saya. \\
\hline \multirow{3}{*}{$\begin{array}{l}\text { Menampilkan diri lebih } \\
\text { baik }\end{array}$} & 3 & Mengedit foto dengan aplikasi tertentu agar terlihat menarik. \\
\hline & 4 & $\begin{array}{c}\text { Memilih foto terbaik untuk diunggah di media sosial agar banyak orang } \\
\text { menyukainya. }\end{array}$ \\
\hline & 9 & Menampilkan foto-foto penuh kebahagiaan. \\
\hline \multirow{4}{*}{ Menutupi identitas } & 5 & Memiliki lebih dari satu akun media sosial dengan identitas berbeda. \\
\hline & 6 & Menikmati berpura-pura menjadi orang lain di media sosial. \\
\hline & 7 & Memakai data diri orang lain pada akun media sosial saya. \\
\hline & 10 & $\begin{array}{l}\text { Sangat jarang menampilkan status, namun sering menyukai dan } \\
\text { mengomentari unggahan orang lain. }\end{array}$ \\
\hline
\end{tabular}

\section{Prosedur}

Pengambilan data dilakukan pada bulan September sampai November 2019 dengan menyebarkan kuesioner menggunakan Google Form (daring). Tautan kuesioner disebarkan ke berbagai komunitas di Jabodetabek, seperti universitas-universitas yang tergabung dalam Konsorsium Psikologi Ilmiah Nusantara (KPIN), yaitu Universitas Persada Indonesia YAI, 
Universitas Pembangunan Jaya, Universitas Bhayangkara Jakarta Raya, juga disebarkan pada masyarakat umum.

\section{Teknik Analisis}

Untuk mendapatkan alat ukur yang baik, maka dilakukan uji validitas dan reliabilitas. Uji reliabilitas dilakukan untuk melihat keandalan atau keajegan alat ukur. Uji reliabilitas ini juga dapat menjadi alat estimasi variasi kesalahan pada sebuah pengukuran, di mana semakin besar kesalahan pengukuran menunjukkan semakin rendahnya koefisien reliabilitas (Chadha, 2009; Rust \& Golombok, 2009). Pengujian validitas isi dari butir pada skala ini dilakukan oleh expert judgment dosen pengampu Psikologi Sosial. Sementara itu, uji keterbacaan dilakukan oleh 10 orang pengguna media sosial untuk mengetahui apakah isi butir kuesioner dapat dipahami, sebelum nantinya kuesioner tersebut disebarkan pada partisipan. Setelah itu, peneliti menyebar kuesioner kepada partisipan sesuai dengan tujuan penelitian. Data yang telah diperoleh kemudian dianalisis untuk melihat gambaran mengenai validitas dan reliabilitas dari skala Deception Behavior in Social Media yang disusun.

Untuk pengujian reliabilitas, peneliti menggunakan metode perhitungan koefisien alfa, yaitu metode yang paling populer dalam mengukur konsistensi internal (Murphy \& Davidshofer, 2001). Batasan reliabilitas yang baik adalah minimal .7 (Chadha, 2009), namun untuk pengujian awal alat ukur koefisien reliabilitas berkisar .6-.7 masih dapat diterima. Pengujian selanjutnya adalah uji validitas. Dalam penelitian ini, uji validitas dilakukan menggunakan Principal Component Analysis (PCA) yang diolah dengan program JASP 0.11.1.0 untuk melihat apakah butir-butir yang dikonstruksi sesuai dengan jenis yang ada pada teori. Setelah melakukan uji PCA, peneliti melanjutkan dengan pengujian Confirmatory Factor Analysis (CFA) untuk melihat kesesuaian butir dengan indikator. Uji CFA ini berguna untuk memastikan bahwa sebuah konstruk memiliki kecocokan dalam suatu model pengukuran (Hair dkk., 2010; Hu \& Bentler, 1999). Kriteria model fit untuk alat ukur dilihat berdasarkan pendapat $\mathrm{Hu}$ dan Bentler (1999), yaitu Tucker-Lewis Index $(\mathrm{TLI}=\mathrm{NNFI})$ dan Comparative Fit Index $(\mathrm{CFI}) \geq .95$, Goodness of Fit Index $(\mathrm{GFI}) \geq .90$, dan Root Mean Square Error of Approximation (RMSEA) $\leq .08$. 


\section{ANALISIS DAN HASIL}

\section{Analisis Butir}

Hasil analisis reliabilitas Cronbach's Alpha diperoleh sebesar .681 $(M=29.348 ; S D=$ 4.718) untuk 10 pernyataan skala Deception Behavior in Social Media. Satu butir dieliminasi, yaitu butir nomor 10 (mengunggah suatu konten di media sosial tanpa pertimbangan) karena memiliki nilai corrected item-total correlation di bawah .2. Meskipun demikian, alat tes ini masih dianggap cukup reliabel karena koefisien Cronbach's Alpha yang dihasilkan mendekati .70. Sementara itu, jangkauan koefisien corrected item-total correlation dari 10 pernyataan ini adalah .219-.538.

\section{Analisis Faktor}

Berdasarkan hasil analisis terhadap butir-butir skala dengan menggunakan PCA, maka yang lolos analisis butir nampak seperti yang terlihat pada Tabel 3.

Tabel 3.

Component Loadings butir alat ukur menurut Principal Component Analysis

\begin{tabular}{|c|c|c|c|c|}
\hline Jenis & No & Yang saya lakukan di media sosial antara lain & RC1 & $\mathbf{R C 2}$ \\
\hline \multirow{4}{*}{$\begin{array}{l}\text { Menyamarkan } \\
\text { identitas }\end{array}$} & 2 & $\begin{array}{l}\text { Menampilkan foto-foto yang bukan diri saya pada media } \\
\text { sosial. }\end{array}$ & .569 & \\
\hline & 5 & $\begin{array}{l}\text { Memiliki lebih dari satu akun media sosial dengan data } \\
\text { diri berbeda. }\end{array}$ & .66 & \\
\hline & 6 & $\begin{array}{l}\text { Menikmati berpura-pura menjadi orang lain di media } \\
\text { sosial. }\end{array}$ & .845 & \\
\hline & 7 & Memakai data diri orang lain pada akun media sosial saya. & .797 & \\
\hline \multirow{4}{*}{$\begin{array}{l}\text { Menampilkan diri } \\
\text { lebih baik }\end{array}$} & 1 & $\begin{array}{c}\text { Menampilkan status sosial yang lebih tinggi agar terlihat } \\
\text { baik bagi orang lain }\end{array}$ & & .557 \\
\hline & 3 & $\begin{array}{c}\text { Mengedit foto dengan aplikasi tertentu agar terlihat } \\
\text { menarik. }\end{array}$ & & .596 \\
\hline & 4 & $\begin{array}{c}\text { Memilih foto terbaik untuk di unggah di media sosial agar } \\
\text { banyak orang menyukainya. }\end{array}$ & & .78 \\
\hline & 9 & Menampilkan foto-foto penuh kebahagiaan & & .639 \\
\hline
\end{tabular}

Berdasarkan tabel hasil PCA di atas, terdapat delapan butir yang lolos. Masing-masing butir mengelompok sesuai jenisnya dengan skor $\mathrm{RC}>.5$ dan diketahui bahwa butir 8 yang berbunyi "Menggunakan nama akun yang berbeda dengan nama asli saya" tidak masuk ke dalam dua dimensi yang terbentuk. Hal ini dapat terjadi karena pada saat membuat akun, banyak pengguna 
media sosial tidak menggunakan nama asli karena kesamaan nama dengan orang lain atau untuk menjaga privasi. Berdasarkan hasil analisis ini, dimensi yang dikemukakan Utz (2005) dapat dikelompokkan menjadi dua jenis, yaitu menutupi identitas dan menampilkan diri lebih baik.

Berdasarkan pengelompokkan tersebut, maka peneliti melakukan uji CFA untuk melihat kesesuaian butir dengan dimensi yang terbentuk dan untuk memastikan bahwa konstruk memiliki kecocokan pada suatu model pengukuran. Hasil uji CFA first order menunjukkan bahwa model pengukuran dapat diterima dengan RMSEA $=.05 ; \mathrm{GFI}=.97 ; \mathrm{CFI}=.95 ; \mathrm{TLI}=.92, \chi_{2} / \mathrm{df}=2.54$. Dengan demikian, dapat disimpulkan bahwa data yang diperoleh dari penelitian ini sesuai dengan model teori yang diajukan. Model pengukuran ditunjukkan dalam Figur 1.

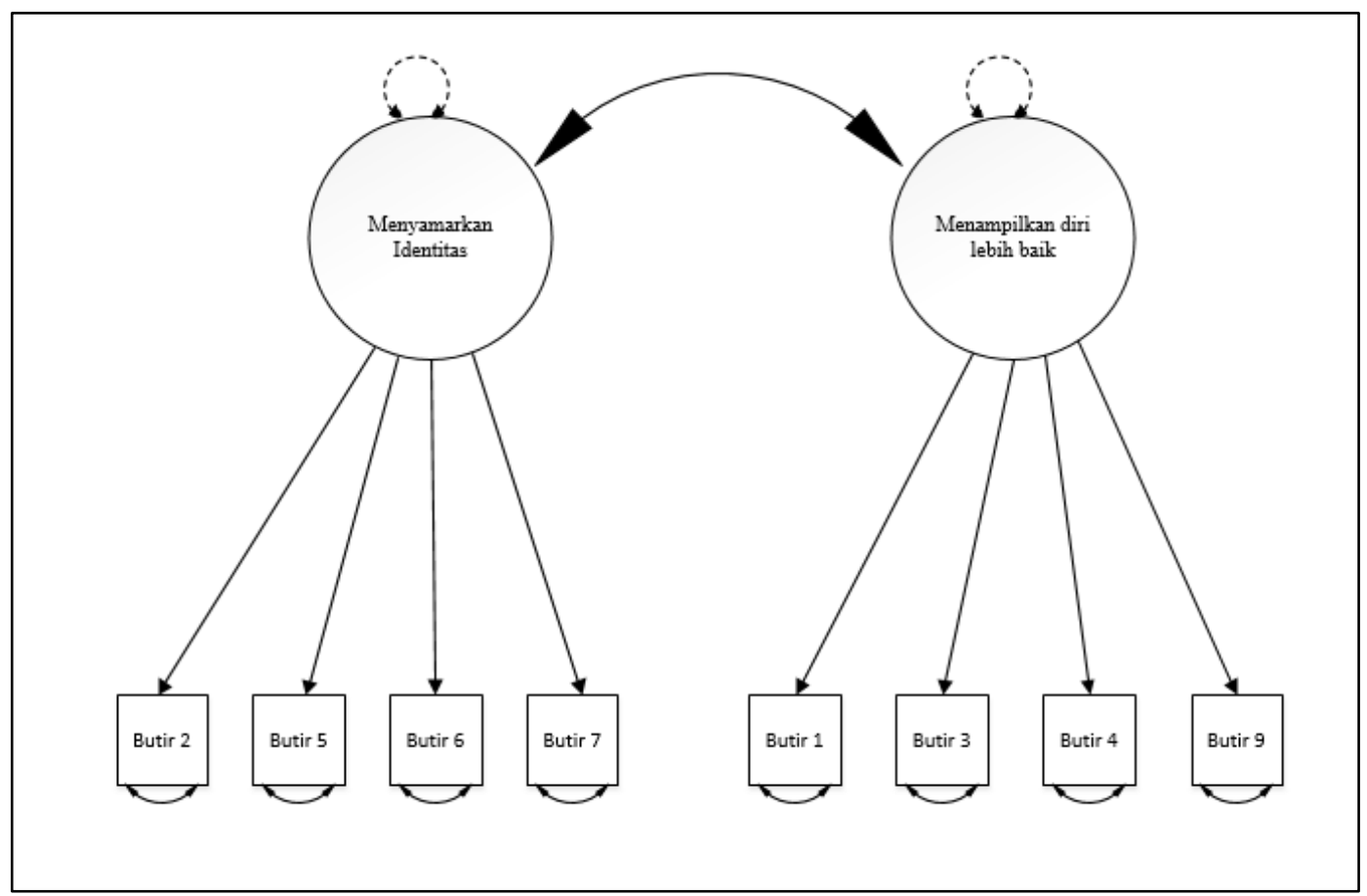

Figur 1. Hasil Uji CFA Dua Dimensi Alat Ukur Deception Behavior in Social Media

\section{DISKUSI}

Skala Deception Behavior in Social Media merupakan skala yang dikonstruksi oleh peneliti berdasarkan teori Utz (2005). Utz (2005) mengemukakan tiga jenis deception behavior pada dunia maya, yaitu mengubah identitas, menampilkan diri lebih baik, dan menutupi identitas. Hasil uji reliabilitas menunjukkan setiap dimensi memiliki reliabilitas yang cukup baik. Hal ini menunjukkan bahwa skala Deception Behavior in Social Media cukup reliabel. Namun, berdasarkan uji PCA 
dapat diidentifikasi bahwa respons terhadap butir-butir yang ada hanya mengelompok pada dua dimensi. Pernyataan butir-butir terkait mengubah identitas dan menutupi identitas menjadi tumpang-tindih, sehingga keduanya dapat dijadikan satu dimensi deception behavior. Dari hasil PCA, terdapat dua dimensi deception behavior yang relevan dengan teori Utz (2005). Dimensi pertama adalah menutupi atau mengubah identitas dan dimensi kedua adalah menampilkan diri lebih baik. Analisis berikutnya dengan melakukan uji CFA untuk mengidentifikasi apakah data yang ada di lapangan sesuai dengan model penelitian.

Berdasarkan hasil analisis di atas, dapat dikatakan bahwa skala Deception Behavior in Social Media ini sudah cukup memadai sebagai properti psikometri. Skala ini valid untuk mengukur konstruk deception behavior dan memiliki konsistensi internal yang cukup baik pula. Selain itu, skala ini disusun secara khusus untuk para pengguna media sosial aktif. Dengan kemajuan teknologi saat ini, media sosial menjadi bagian yang tidak dapat lepas dari kehidupan sehari-hari dan menjadi penting dalam berinteraksi sosial, khususnya bagi masyarakat modern. Hal ini sejalan dengan pendapat Dunne dkk. (2010) yang menyebutkan bahwa keberadaan media sosial secara konsisten terus meningkat dalam kurun waktu lima tahun terakhir ini yang secara aktif digunakan oleh para pemuda. Berikutnya, temuan penelitian Szwedo dkk. (2012) menyatakan bahwa penggunaan media sosial dapat memprediksi perubahan penyesuaian psikologis pada pemuda. Hubungan antara komunikasi online dan penyesuaian psikologis terletak pada bagaimana para pengguna memakai media sosialnya untuk mengembangkan persahabatan. Bagi yang mungkin mengalami kendala dalam menjalin relasi secara langsung dalam kehidupannya sehari-hari, maka peluang untuk berteman melalui media sosial ini menjadi pilihan menarik untuk berkoneksi dengan orang lain.

Namun demikian, penelitian ini masih memiliki beberapa keterbatasan. Pertama, penyusunan butir-butirnya berpotensi tumpang-tindih antarjenis deception behavior, sehingga peneliti sedikit mengalami kesulitan untuk membuat banyak butir yang bervariasi, terutama bila dilakukan uji analisis faktor yang berkemungkinan butir-butir tidak mengelompok pada faktornya atau mengelompok pada faktor lain. Kedua, secara teoretis pemahaman tentang jenis deception behavior dalam hal mengubah identitas dan menutupi identitas tampak saling berkaitan. Misalnya, bila seseorang menampilkan foto-foto yang bukan dirinya pada akun media sosialnya, dapat saja dikatakan bahwa hal tersebut mengubah identitas, tetapi juga dapat dikatakan sebagai menutupi identitas dirinya. Hal-hal semacam ini yang membuat butir-butir yang dikonstruk menjadi lebih rumit untuk dapat dibedakan secara jelas. Oleh karena itu, penelitian selanjutnya diharapkan dapat 
membuat butir-butir yang lebih bervariasi dan berdaya beda agar diperoleh lebih banyak butir dengan hasil analisis yang lebih baik lagi. Selain itu, ada kemungkinan ketika artikel ini ditulis muncul teori baru yang juga dapat digunakan untuk mengembangkan skala dan dapat divariasikan dengan karakteristik partisipan atau yang berkaitan dengan jumlah jam online dan jumlah teman di media sosialnya.

\section{SIMPULAN DAN SARAN}

\section{Simpulan}

Studi penyusunan skala Deception Behavior in Social Media yang butir-butirnya disusun sendiri oleh peneliti ini dianggap sudah memiliki standar psikometri yang cukup baik. Hasil uji PCA membuktikan bahwa skala ini adekuat dengan dua jenis deception behavior, yaitu mengubah atau menutupi identitas dan menampilkan diri lebih baik. Begitupun dengan hasil uji CFA yang sudah cukup memadai, sehingga dapat disimpulkan bahwa skala Deception Behavior in Social Media ini sudah dapat digunakan pada penelitian psikologi, khususnya yang berhubungan dengan wilayah siber.

\section{Saran Teoretis}

Penelitian selanjutnya disarankan dapat memfokuskan pada partisipan khusus remaja Indonesia guna memotret gambaran deception behavior remaja Indonesia yang diketahui sangat aktif dalam menggunakan media sosialnya, baik secara positif atau negatif (Selviana, 2016) maupun menggunakan teori lain terkait deception behavior. Selain itu, diharapkan penelitian berikutnya dapat berhasil melibatkan ketiga jenis pengukuran deception behavior sesuai teori aslinya, mengingat pada penelitian ini hanya dua jenis yang dapat terpakai untuk mengukur deception behavior di media sosial.

\section{Saran Praktis}

Berdasarkan analisis yang telah dilakukan, skala Deception Behavior in Social Media ini sudah memenuhi standar psikometri yang memadai, sehingga sudah dapat dimanfaatkan untuk mengukur deception behavior di dunia maya. 


\section{UCAPAN TERIMA KASIH}

Ucapan terima kasih ditujukan kepada Konsorsium Psikologi Ilmiah Nusantara (KPIN) yang telah mendanai penelitian ini sebagai program Riset Kolaborasi Dosen antar Universitas Anggota KPIN guna menunjang produktivitas dosen dalam hal penelitian dan publikasi ilmiah.

\section{REFERENSI}

Burgoon, J. K., \& Levine, T. R (2010). Advances in deception detection. Sage.

Chadha, N. K. (2009). Applied psychometry. Sage.

Carson, T. L. (2010). Lying and deception: Theory and practice. Oxford University Press.

Dunne, A., Lawlor, M. A., \& Rowley, J. (2010). Young people's use of online social networking sites - A uses and gratifications perspective. Journal of Research in Interactive Marketing, $4,46-58$.

Knapp, M. L., Mcglone, M. S., Griffin, D. J., \& Earnest, W. (2016). Lying and deception in human interaction. Kendall Hunt.

Hair, Jr. J. F., Black, W. C., Babin, B. J., \&Anderson, R. E. (2010). Multivariate data analysis. Pearson.

Hayuputri, F. M. (2019). Akun palsu di media sosial dalam kaitannya dengan deindividuasi. Buletin KPIN， 5(19). https://buletin.k-pin.org/index.php/arsip-artikel/477-akun-palsu-di-mediasosial-dalam-kaitannya-dengan-deindividuasi.

Hootsuite. (2019, September 12). Data tren internet dan media sosial 2019 di Indonesia. Ditemu kembali dari https://andi.link/hootsuite-we-are-social-indonesian-digital-report-2019/.

Hu, L. T., \& Bentler, P. M. (1999). Cut-off criteria for fit indexes in covariance structure analysis: Conventional criteria versus new alternatives. Structural Equation Modeling, 6(1), 1-55.

Moningka, C. (2017). Self-comparison: The self in digital world. Dalam M. F. Wright (Ed.), Identity, sexuality, and relationships among emerging adults in the digital age (hlm. 18-26). IGI Global.

Murphy, K. R., \& Davidshover, C. O. (2001). Psychological testing: Principles and applications (5th ed.). Prentice Hall. 
Rust, J., \& Golombok, S. (2009). Modern psychometrics: The science of psychological assessment (3rd ed.). Routledge.

Sanderson, C. A. (2010). Social psychology. John Wiley \& Sons.

Selviana. (2016). Empati dan penggunaan situs jejaring sosial sebagai faktor dalam membentuk moral remaja. Jurnal Psikologi Ulayat, 3(2), 143-157. https://doi.org/10.24854/jpu22016-68

Szwedo, D. E., Mikami, A., Y., \& Allen, J. P. (2012). Social networking site use predicts changes in young adults' psychological adjustment. Journal of Research on Adolescence, 22(3), 453466. https://doi.org/10.1111/j.1532-7795.2012.00788.x

Utz, S. (2005). Types of deception and underlying motivation. Social Science Computer Review, 23(1), 49-56. https://doi.org/10.1177/0894439304271534

Whitty, M. T., \& Young, G. (2017). Cyberpsychology: The study of individuals, society and digital technologies. Wiley Blackwell. 